\title{
Relevant information in the era \\ of a pandemic: ways of broad-casting and peculiarities of perception
}

E. V. Koneva ${ }^{1}$, V. K. Solondaev ${ }^{1}$

${ }^{1}$ P. G. Demidov Yaroslavl State University, 14 Sovetskaya str., Yaroslavl 150003, Russian Federation

DOI: 10.18255/1996-5648-2021-4-592-601

Research article

Full text in Russian

The choice of the subject of the article is due to the fact that numerous recent publications actively analyze the reaction of people to information about COVID-19, butdonotinvestigate thestage of actually receiving and understanding this information by citizens. Using the example of the publication in the regional electronic edition of the telegram channel of the regional administration, some factors affecting the perception and understanding of information concerning the health of schoolchildren and teachers are studied. An empirical characteristic of the change in understanding is given when the logic of constructing a message changes - the combination of substantive and procedural logic. Possible directions for further study of the problem are formulated.

Keywords: information material; substantive logic; procedural logic; trust in information; verbal content; non-verbal content

\section{INFORMATION ABOUT AUTHORS}

\author{
Koneva, Elena V. | E-mail: ev-kon@yandex.ru \\ Doc. Sc. (Psychology), Professor \\ Solondaev, Vladimir K. | E-mail: solond@yandex.ru \\ Cand. Sc. (Psychology), Associate Professor
}




\section{Актуальная инфрормация \\ в эпоху пандемии: способы трансляции \\ и особенности восприятия}

Е. В. Конева ${ }^{1}$, В. К. Солондаев ${ }^{1}$

${ }^{1}$ Ярославский государственный университет им. П. Г. Демидова, ул. Советская, 14, Ярославль, 150003, Российская Федерация

DOI: 10.18255/1996-5648-2021-4-592-601

УДК 159.9

Научная статья

Полный текст на русском языке

Выбор тематики статьи обусловлен тем обстоятельством, что в многочисленных публикациях последнего времени активно анализируется реакция людей на информацию о COVID-19, но не изучается этап собственно получения и понимания этой информации. На примере публикации в региональном электронном издании исследованы некоторые факторы, влияющие на восприятие и понимание информации, которая касается здоровья школьников и педагогов. Дана эмпирическая характеристика изменения понимания при изменении логики построения сообщения - соединении субстанциальной и процессуальной логик. Сформулированы возможные направления дальнейшего изучения проблемы.

Ключевые слова: информационный материал; субстанциальная логика; процессуальная логика; доверие к информации; вербальный контент; невербальный контент

\section{ИНФОРМАЦИЯ ОБ АВТОРАХ}

Конева, Елена Витальевна $\mid$ E-mail: ev-kon@yandex.ru

Доктор психологических наук, профессор

Солондаев, Владимир Константинович

E-mail: solond@yandex.ru

Кандидат психологических наук, доцент

Процессы получения и анализа информации потребителем в условиях пандемии приобрели не только повышенное значение, но и особенности, в меньшей степени свойственные им в «доковидный» период. Среди этих особенностей разные авторы отмечают следующее. Во-первых, пережива(C) Конева Е. В., Солондаев В. К., 2021

Статья открытого доступа под лицензией CС BY (https://creativecommons.org/licenses/by/4.0/) 
Конева Е. В., Солондаев В. К.

ние эпидемической угрозы с высокой степенью вероятности снижает доверие к информации, получаемой из СМИ и из других источников [1]. Во-вторых, потребление информации в период пандемии выполняет защитную функцию, способствуя регулированию психического состояния, в частности снижению тревоги [2]. В-третьих, уникальность современной ситуации заключается в том, что информационный фон не только выступает в роли транслятора сведений и даже не только в роли побудителя к определенным формам поведения (например, к вакцинированию), но и фрормирует и конструирует новые ценности [3]. Наконец, при наличии огромного инфрормационного потока существуют значительные трудности верификации информации [4], в результате чего зафиксировано новое явление, обозначенное как инородемия [3, 5].

Изучая особенности восприятия потребителями информации о коронавирусной инфекции, ученые закономерно обращают внимание на возможности публикаций оказать на потребителей воздействие, способное убедить их в необходимости защитных противовирусных мер, в том числе вакцинирования. Определенные формы презентации информации в большей или меньшей степени способствуют доверию потребителей к рекомендациям официальных лиц $[3,6]$ и, соответственно, стимулирует выполнение этих рекомендаций. При этом тематика психологического воздействия в СМИ и других источниках не исчерпывается намеренно применяемыми автором средствами. Во многих случаях актуален лозунг «не навреди», то есть при построении инорормации важно иметь в виду, что сообщение может оказать негативное влияние на психологическое состояние и когнитивную сореру потребителей независимо от мотивации автора.

В нашем исследовании мы преследовали цель выявить, каким образом воспринимается информация, опубликованная в сентябре 2020 г. в одном из региональных электронных СМИ, в сравнении с информацией того же содержания, построенной с учетом рисков негативного психологического воздействия на потребителей.

Экспериментальный материал: оригинальный и модифицированные тексты ${ }^{1}$ (табл. 1).

Модифицированный вариант отличается от оригинального двумя деталями, отвечающими закономерностям процессуальной логики. В отличие от субстанциональной логики, в которой построено большинство официальных текстов, процессуальная логика основывается на процессах, действиях [7]. Одна логика не «лучше» и не «хуже» другой, однако восприятие и понимание текстов, построенных в разных логиках, гипотетически должно различаться.

${ }^{1}$ Удалены географическое название, номер образовательной организации, фамилия и имя официального лица. 
Оригинальный и модифицированный тексты

\begin{tabular}{|c|c|}
\hline Оригинальная информация & Модифицированная инорормация \\
\hline $\begin{array}{l}\text { Во избежание распространения ОРВИ, } \\
\text {... школа № ... отправлена на карантин. } \\
\text { В образовательной организации за- } \\
\text { фиксирован рост заболевших. } \\
\text { В связи со сложной эпидемиологиче- } \\
\text { ской ситуацией, а также во избежа- } \\
\text { ние распространения ОРВИ школь- } \\
\text { ники и педагоги ушли на карантин } \\
\text { до } 5 \text { октября, - отметила директор де- } \\
\text { партамента образования ... области .... } \\
\text { О переводе на дистанционное об- } \\
\text { учение речи не идет, это ограни- } \\
\text { чительные меры, которье при- } \\
\text { меняются при сезонном подъеме } \\
\text { заболеваемости в целях разобщения } \\
\text { детей и минимизации контактов. В учеб- } \\
\text { ную программу будут внесены поправ- } \\
\text { ки, чтобы скорректировать процесс. } \\
\text { В образовательной организации будет } \\
\text { проведена полная дезинфекция зда- } \\
\text { ния в противовирусном режиме с при- } \\
\text { влечением профильного предприятия. } \\
\text { По состоянию на 28 сентября } \\
\text { в ... школе № ... также выявлен по- } \\
\text { ложительный диагноз на коронави- } \\
\text { рус у } 19 \text { школьников и } 3 \text { педагогов. } \\
\text { Полная инорормация о состоянии учеб- } \\
\text { ного процесса в регионе в связи с коро- } \\
\text { навирусом размещена на сайте депар- } \\
\text { тамента образования ... области. }\end{array}$ & 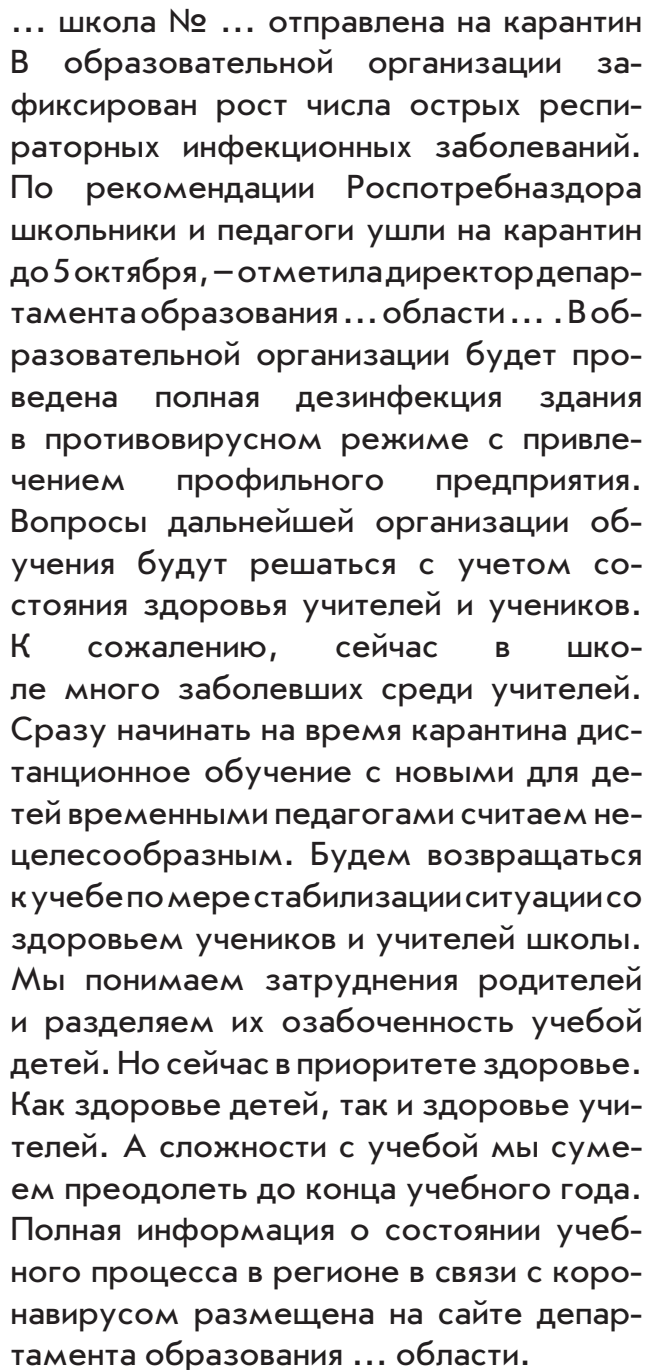 \\
\hline
\end{tabular}

Для проверки этого предположения из основного текста, во-первых, были исключены те единицы информации, которые могут провоцировать у читателей «путаницу» в уровнях обобщения: COVID-19 также относится к категории ОРВИ, а в исходном тексте эти два понятия расположены вперемешку. Во-вторых, добавлена эмоционально окрашенная информация: негативное отношение автора к происходящему; сожаление по поводу де- 
Конева Е. В., Солондаев В. К.

зорганизации учебного процесса и выражение намерения изменить ситуацию; упоминание ценности здоровья.

Методика исследования. Испытуемым предлагалось оценить каждый из текстов по следующим параметрам: понятность информации, достоверность информации, вероятность благоприятного развития описанной ситуации в плане продолжения учебы. Кроме того, необходимо было указать, какие чувства, впечатления вызывает у испытуемых прочитанная информация.

Выборка. В опросе приняли участие 48 испытуемых - студенты фракультета психологии, из них 43 женщины, 5 мужчин. Возраст испытуемых 18-20 лет.

Обработка результатов. Ответы на вопрос: «Какие чувства, впечатления вызывает у Вас прочитанная информация?» - обрабатывались с помощью частотного анализа. Отсутствие ответа также рассматривалось как единица анализа. В отдельных случаях испытуемые давали несколько ответов на вопрос. В результате по оригинальному тексту (1-я серия) было получено 50 ответов, по модифицированному (2-я серия) - 48 ответов.

Различия между результатами 1-й и 2- й серий заключаются в следующем (табл. 2).

Таблица 2

Различия в ответах на вопрос:

«Какие чувства, впечатления вызывает у Вас прочитанная информация?»

\begin{tabular}{|c|c|c|}
\hline № & Оригинальная информация & Модифицированная информация \\
\hline 1. & $\begin{array}{l}\text { В } 10 \% \text { ответов упоминаются чув- } \\
\text { ства грусти, печали }\end{array}$ & $\begin{array}{l}\text { Не упоминаются чувства грусти, } \\
\text { печали }\end{array}$ \\
\hline 2. & $\begin{array}{l}14 \text { \% ответов выражают безраз- } \\
\text { личие, чувство обыденности, уста- } \\
\text { лость от подобной инорормации } \\
\text { или не отвечают на вопрос }\end{array}$ & $\begin{array}{l}\text { Ответы, выражающие безразли- } \\
\text { чие, чувство обыденности, уста- } \\
\text { лость от подобной иноормации, } \\
\text { отсутствуют }\end{array}$ \\
\hline 3. & $\begin{array}{l}6 \% \text { ответов содержат упрек } \\
\text { в адрес руководителей образо- } \\
\text { вательных структур, центральной } \\
\text { власти; одобрение их действий } \\
\text { отсутствует }\end{array}$ & $\begin{array}{l}\text { Упреки в адрес каких-либо офици- } \\
\text { альных структур отсутствуют; одо- } \\
\text { брение их действий выражено в } 8 \text { \% } \\
\text { ответов }\end{array}$ \\
\hline 4. & \multicolumn{2}{|c|}{$\begin{array}{l}\text { В } 23 \text { \% ответов отмечено более высокое качество модифицированной } \\
\text { информации: «Более легко воспринимаема, т. к. написана более не- } \\
\text { формально»; “Чувствуется забота о школьниках и педагогах и понима- } \\
\text { ние трудности сложившейся ситуации»; «Благодарность за то, что в прио- } \\
\text { ритете здоровье»; «Оперативное решение проблемы радует» }\end{array}$} \\
\hline
\end{tabular}

Восприятие понятности информационных сообщений фиксировалось по шкале от 1 (непонятно) до 5 (полностью понятно). Средняя оценка понят- 
ности первого сообщения 4,75, станд. откл. 0,56. Средняя оценка понятности второго сообщения 4,40, станд. откл. 0,81. Из оценок понятности второго сообщения каждым испытуемым вычитались оценки, данные тем же испытуемым первому сообщению; результат оценивался по критерию Вилкоксона в модификации Манна-Уитни.

Второе инфрормационное сообщение было воспринято испытуемыми как менее понятное. Медиана разности оценок составила минус 0,999 балла; $\mathrm{V}=44 ;$ p-value $=0,02 ; 95$-процентный доверительный интервал разности: $[-1,5 ; 0,001]$.

Восприятие достоверности информационных сообщений фриксировалось по шкале от 1 (недостоверно) до 7 (полностью достоверно). Средняя оценка достоверности первого сообщения 5,19, станд. откл. 1,14 . Средняя оценка достоверности второго сообщения 5,31, станд откл. 1,41. Из оценок достоверности второго сообщения каждым испытуемым вычитались оценки, данные тем же самым испытуемым первому сообщению; результат оценивался по критерию Вилкоксона в модификации Манна-Уитни.

Воспринимаемая достоверность не изменилась. Медиана разности менее 0,001 балла; $\mathrm{V}=261 ; \mathrm{p}$-value = 0,55; 95-процентный доверительный интервал разности: [0,5; 0,99].

Прогноз развития событий - «Насколько вероятно, на Ваш взгляд, благоприятное развитие описанной ситуации в плане учебы?» - фриксировался по шкале от 1 (будут большие проблемы) до 7 (ученики закончат год как обычно). Средняя оценка прогноза по первому сообщению 3,63, станд. откл. 1,50. Средняя оценка прогноза по второму сообщению 5,31, станд. откл. 1,56. Из оценок прогноза на основании второго сообщения каждым испытуемым вычитались оценки прогноза, данные тем же самым испытуемым первому сообщению; результат оценивался по критерию Вилкоксона в модификации Манна-Уитни.

Прогноз на основании второго сообщения оказался значимо более благоприятным. Это можно объяснить построением текста в П-логике, картина мира которой строится из динамически текущих процессов. Медиана разности оценок составила 1 балл; $\mathrm{V}=319 ; \mathrm{p}$-value $=0,00 ; 95$-процентный доверительный интервал разности: [0,99; 1,99$]$.

Анализируя в совокупности развернутые суждения и ответы, данные испытуемыми с использованием оценочных шкал, можно заключить, что модифицированное сообщение рассматривается испытуемыми как более эмоционально позитивное и одновременно как менее понятное. Это не означает, что коммуникативная стратегия, использованная в модифицированном тексте, оказалась малоэффективной. В условиях дефицита инорормации иллюзорная, преждевременная ясность вводит в заблуждение больше, чем осознаваемая неопределенность, так как провоцирует неэ- 
Конева Е. В., Солондаев В. К.

форективное планирование. Одной из причин «непонятности» модифицированного сообщения может быть отсылка к пандемии коронавируса, которая присутствовала в нем. Несмотря на то что она была вынесена из основного текста и прямо не находилась в параллели с информацией об ОРВИ, она способствовала противоречивости транслируемых потребителю сведений. Однако базовым фрактором, влияющим на оценку читателями сообщений на столь актуальную тематику, как пандемия COVID-19, по-видимому, является недоверие к официальным источникам. Согласно субстанциальной логике, если в сообщении упоминается коронавирусная инфекция, значит, инорормация, которая в нем содержится, связана с «короной», следовательно, интерпретируется в контексте пандемии независимо от того, что пытается сообщить или доказать читателям автор. Уровень доверия к инорормации о пандемии, как показывает ряд исследований, в целом достаточно низок. Так, согласно данным, полученным в марте - апреле 2020 года [8], $31,5 \%$ испытуемых-студентов считают имеющуюся на тот момент информацию преувеличенной или недостоверной. Причины недоверия средствам массовой инорормации разнообразны и относятся к различным ее разновидностям [9-10].

Что касается большей «оптимистичности», точнее меньшей депрессогенности, модифицированного сообщения, о чем свидетельствует отсутствие в реакциях на него ответов, выражающих грусть, печаль, безразличие, чувство обыденности, усталости от подобной информации, упреков в адрес официальных структур, а также наличие одобрения их действий, то, по-видимому, данный результат необходимо анализировать с учетом социального контекста. Исследование проводилось осенью 2020 года, испытуемыми являлись первокурсники университета - недавние школьники, вновь находящиеся в условиях дистанционного обучения, вызвавшего стрессовые переживания, в частности тревогу и беспокойство. Преодолению тревоги и беспокойства способствуют сведения о процессуальной включенности авторов в описываемые ими события или явления. В модифицированном тексте включенность выражалась в соответствующих фррагментах: «К сожалению, сейчас в школе много заболевших ....» (развернутая фрормулировка в процессуальной логике: болезнь учителей вызывает сожаление автора сообщения - так называемого «спикера»); «Мы понимаем затруднения родителей и разделяем их озабоченность учебой детей» (авторы сообщения прогнозируют, что родители станут выражать недовольство и считают такое поведение закономерным), а также в описании действий по стабилизации ситуации: «Будем возвращаться к учебе ...»; «... сложности с учебой мы сумеем преодолеть до конца учебного года». Процессуальная логика описывает мир как течение процессов. «Будем возвращаться к учебе» озна- 
чает следующее: после прояснения ситуации с ковидом органы управления образованием приступят к решению вопросов учебы.

Кроме того, на позитивную оценку модифицированного, согласно процессуальной логике, текста повлияло то обстоятельство, что в нем фигурировали люди, планирующие или совершающие некие реальные действия. А фриксация на ожидании инициативы в преодолении ситуации отдругихлюдейвыступаетвкачествеодногоизсредствпереживаниятравмы (в данном случае - травмы пандемии) [11]. Вероятно, испытуемые продемонстрировали именно эту характерную для травматического периода закономерность.

Неоднозначность полученных результатов хотя и отражает специфику ситуации, но вызывает вопросы, ответы на которые возможны в ходе дальнейших исследований данной темы. Одним из направлений может быть применение метода Келли для выявления тех конструктов, с помощью которых испытуемые характеризуют воспринимаемый материал спонтанно, не будучи ограничены заданными шкалами. Кроме того, независимо от используемых методик существуют различия в восприятии информации потребителями разных возрастных и социальных групп. Парадоксально, что при наличии работ, посвященных изучению возрастных особенностей восприятия коронавирусной инфекции как явления [12], не уделяется внимания особенностям промежуточного этапа, а именно восприятия информации об эпидемической угрозе, транслируемой СМИ. Другими словами, в цепочке событий и психологических реакций на них, которая может быть обозначена примерно как «реальность - ее отражение в СМИ - восприятие и оценка материалов СМИ - вербальный и поведенческий ответ» упущен этап восприятия и оценки. Соответственно, недостаточно данных о факторах, влияющих на этот процесс. Между тем представление о его возрастных и социально-групповых особенностях позволит повысить эффективность восприятия информации и доверие к ней в тех случаях, когда, по крайней мере в общих чертах, известна целевая аудитория информационного материала.

Кроме того, современные средства передачи информации широко используют невербальную составляющую контента, которая обладает высоковыраженным эмоциональным потенциалом. Он, в свою очередь, может преобладать над когнитивным содержанием и становиться, таким образом, определяющим компонентом сообщения или, по крайней мере, играть роль акцентировки. Так, С. Г. Давыдов со ссылкой на Ю. А. Грибер и В. В. Сухову отмечает, что существенное влияние на восприятие информации о COVID-19 оказывает сложившаяся с самого начала пандемии традиция изображения вызвавшего ее вируса: будучи по своей 
Конева Е. В., Солондаев В. К.

природе бесцветным, он регулярно изображается как яркоокрашенный, что провоцирует негативные эмоции [13].

Возвращаясь к анализируемой нами публикации в новостном электронном издании в контексте ее невербального сопровождения, отметим, что она сопровождалась «грустными смайликами», излишне, на наш взгляд, нагружающими текст дополнительными смыслами. В любом случае и с научной и с практической точек зрения было бы важно исследовать влияние различных вариантов невербального контента в составе информационного материала на его восприятие и оценку.

В качестве вывода отметим, что восприятие сообщения, построенного в процессуальной логике, в целом кардинально не отличается от аналогичного процесса применительно к сообщению, отвечающему закономерностям субстанциональной логики, однако «процессуальное» сообщение оценивается как значимо более позитивное.

\section{Ссылки}

1. Макушева М. О., Нестик Т. А. Социально-психологические предпосылки и эффекты доверия социальным институтам в условиях пандемии // Мониторинг общественного мнения: экономические и социальные перемены. 2020. №. 6 (160). C. 427-447. URL: https://cyberleninka.ru/article/n/sotsialno-psihologicheskiepredposylki-i-effekty-doveriya-sotsialnym-institutam-v-usloviyah-pandemii (дата обращения: 20.09.2021).

2. Тхостов А. Ш., Рассказова Е. И. Психологическое содержание тревоги и профилактики в ситуации инфодемии: защита от коронавируса или «порочный круг» тревоги? // Консультативная психология и психотерапия. 2020. Т. 28, № 2. C. 70-89. DOI: $10.17759 /$ cpp.2020280204

3. Кубрак Т. А., Латынов В. В. Возможности и ограничения инорормационно-психологического воздействия в ситуации пандемии коронавируса // Социальная и экономическая психология. 2020. T. 5, №. 2. С. 84-114. URL: http://soc-econompsychology.ru/engine/documents/document787.pdf (дата обращения: 03.03.2021).

4. Васильева А. В. Первая конференция по инфодемиологии ВОЗ: мультидисциплинарное сотрудничество в противодействии дезинформации в период пандемии COVID - 19 // Обозрение психиатрии и медицинской психологии имени B. M. Бехтерева. 2020. №. 3. С. 93-95. DOI: 10.31363/2313-7053-2020-3-93-95

5. Раренко А. А., Воронцова В. О. Инфодемия в COVID-19 // Социальные и гуманитарные науки. Отечественная и зарубежная литература. Сер. 11, Социология: Рефреративный журнал. 2021. №2. URL: https://cyberleninka.ru/article/n/ infodemiya-v-usloviyah-pandemii-covid-19 (дата обращения: 20.09.2021).

6. Chou W. Y. S., Budenz A. Considering emotion in COVID-19 vac-cine communication: addressing vaccine hesitancy and fostering vaccine confidence//Health communication. 2020. T. 35, №. 14. C. 1718-1722. DOI: 10.1080/10410236.2020.1838096 
7. Смирнов А. В., Солондаев В. К. Процессуальная логика. М.: Садра, 2019. 160 c.

8. Алехин А. Н., Данилова Ю. Ю., Щелкова О. Ю. Особенности психологических реакций в ситуации эпидемической угрозы, транслируемой СМИ // Психология человека в образовании. 2020. T. 2, №. 4. URL: https://cyberleninka.ru/ article/n/osobennosti-psihologicheskih-reaktsiy-v-situatsii-epidemicheskoy-ugrozytransliruemoy-smi (дата обращения: 20.09.2021).

9. Ненашева А. В. Недоверие к источникам информации в период пандемии // Научные труды Северо-Западного института управления РАНХиГС. 2020. Т. 11, №. 3. C. 168-173. URL: https://www.elibrary.ru/item.asp?id=44216486 (дата обращения: 06.09.2021).

10. Jaiswal J., LoSchiavo C., Perlman D. C. Disinformation, misinformation and inequality-driven mistrust in the time of COVID-19: lessons unlearned from AIDS denialism // AIDS and Behavior. 2020. T. 24. C. 2776-2780. DOI: $10.1007 / \mathrm{s} 10461-020-02925-\mathrm{y}$

11. Холмогорова А. Б. Переживание коллективной травмы пандемии: попытка осмысления // Психологическая газета. URL: https:/psy.su/feed/8912/ (дата обращения: 04.08.2021).

12. Восприятие COVID-19 населением России в условиях пандемии 2020 года / Е. И. Первичко, О. В. Митина, О. Б. Степанова [и др.] [Электронный ресурс] // Клиническая и специальная психология. 2020. Т. 9, o 2. С. 119-146. DOI: $10.17759 /$ cpse.2020090206

13. Давыдов С. Г. Двенадцать статей о девятнадцатом ковиде: первая волна исследований медиа и коммуникаций в условиях пандемии // Мониторинг. 2020. № 6 (160). URL: https://cyberleninka.ru/article/n/dvenadtsat-statey-o-devyatnadtsatomkovide-pervaya-volna-issledovaniy-media-i-kommunikatsiy-v-usloviyah-pandemii (дата обращения: 20.09.2021). 